\title{
Micturitional disturbance in patients with Guillain-Barré syndrome
}

Ryuji Sakakibara, Takamichi Hattori, Satoshi Kuwabara, Tomonori Yamanishi, Kosaku Yasuda

\begin{abstract}
Objectives-To examine the frequency and pathophysiology of micturitional disturbance in patients with Guillain-Barré syndrome.

Methods-Micturitional symptoms were noted and neurological examinations made repeatedly during admission to hospital of patients with clinical and neurophysiologically definite Guillain-Barré syndrome. Urodynamic studies consisted of uroflowmetry, measurement of residual urine, urethral pressure profilometry, medium fill water cystometry, and external sphincter EMG.
\end{abstract}

Results-Seven of 28 (25\%) patients with Guillain-Barré syndrome showed micturitional disturbance. The symptoms included voiding difficulty in six, urinary retention in three, nocturnal urinary frequency in three, and urge incontinence in two. These micturitional symptoms appeared after weakness occurred, and improved gradually along with the neurological signs. All three patients who showed retention became able to urinate. Urodynamic studies were made on four symptomatic patients two of whom underwent repeated study. Disturbed bladder sensation was noted in one patient, bladder areflexia in one, and absence of the bulbocavernosus reflex in one. Cystometry showed decreased bladder volume in two and bladder overactivity in two, one of whom had urge urinary incontinence and the other urinary retention.

Conclusions-A quarter of the patients with Guillain-Barré syndrome tend to have micturitional disturbance. The patients studied had evacuation and storage disorders, as well as bladder areflexia and disturbed bladder sensation indicative of peripheral types of parasympathetic and somatic nerve dysfunction. Decreased bladder volume with bladder overactivity but no evidence of CNS involvement was also found, evidence that bladder overactivity also occurs in peripheral nerve lesions with probable pelvic nerve irritation.

(F Neurol Neurosurg Psychiatry 1997;63:649-653)

Keywords: Guillain-Barré syndrome; urinary incontinence; urodynamic study; autonomic dysfunction; bladder overactivity
Autonomic disturbances are well known in Guillain-Barré syndrome, ${ }^{12}$ either autonomic overactivity or underactivity. Cardiovascular abnormalities are the most common. More than $60 \%$ of the patients studied had ECG abnormalities, labile hypertensive or hypotensive arterial pressure, postural hypotension, or bradyarrhythmias or tachyarrhythmias. ${ }^{3}$ Micturitional disturbance, a rare phenomenon, is not considered to be a factor in Guillain-Barré syndrome, ${ }^{45}$ although it was found in three of 12 patients $(25 \%)$ in the original reports of Guillain et $a l^{67}$ Urodynamic data on the mechanism of micturitional disturbance is available in only a few reports. ${ }^{8-10}$ Bladder areflexia and disturbed bladder sensation are common findings, and non-relaxing urethral sphincter with neurogenic change is another. ${ }^{8}$ Wheeler et $a l^{9}$ also noted bladder overactivity, but some of their patients had extensor plantar responses, which raises questions about the diagnosis. Recently, we also found bladder overactivity in cliniconeurophysiologically definite cases of Guillain-Barré syndrome. We here describe our findings on the micturitional histories of patients with Guillain-Barré syndrome and the urodynamic studies done.

\section{Patients and methods}

This is a retrospective study, in which we reviewed the records of 28 patients with Guillain-Barré syndrome, all of whom satisfied the Guillain-Barré syndrome diagnostic criteria ${ }^{45}$ except for "sphincter disturbance". Nineteen were male and nine were female, mean age 37, range 8-69 years (table 1 ). Antecedent upper respiratory infection was noted in 12, diarrhoea in eight, herpes zoster in one, and no signs in seven. Antecedent diarrhoea was not exclusively associated with the axonal form in our patients with Guillain-Barré syndrome. All the patients experienced acute exacerbation of the motor dominant clinical and neurophysiological abnormalities during the first two weeks. The weakness grading conformed to the disability scale reported by the Guillain-Barré Syndrome Steroid Trial Group ${ }^{11}$; mild (able to walk $5 \mathrm{~m}$ across an open space without assistance; grades 1-2) in five; moderate (able to walk $5 \mathrm{~m}$ across an open space with the help of one person and a waist level walking frame, stick, or sticks; grade 3) in 11, and severe (chairbound, bedbound, or assisted ventilation required; grades 4-5) in 12. Eight of the patients required assisted ventilation and had indwelling urinary catheters. Sensory disturbance was absent in 12, superficial in nine, deep in one, 
Table 1 Patients and results of micturitional hiatories

\begin{tabular}{|c|c|c|c|c|c|c|c|c|c|c|c|c|c|c|}
\hline \multirow{2}{*}{$\begin{array}{l}\text { Patient } \\
\text { No }\end{array}$} & \multirow{2}{*}{$\begin{array}{l}\text { Age } \\
\text { (y) }\end{array}$} & \multirow[b]{2}{*}{ Sex } & \multirow{2}{*}{$\begin{array}{l}\text { Anticedent } \\
\text { infection }\end{array}$} & \multirow{2}{*}{$\begin{array}{l}\text { Segmental } \\
\text { demyelination } \\
\text { on NCS }\end{array}$} & \multirow{2}{*}{$\begin{array}{l}\text { Cytoalbumino } \\
\text { dissociation }\end{array}$} & \multirow{2}{*}{$\begin{array}{l}\text { Weakness of } \\
\text { extremities }\end{array}$} & \multicolumn{2}{|c|}{ Disturbed sensation } & \multirow{2}{*}{$\begin{array}{l}\text { Cranial } \\
\text { involvement }\end{array}$} & \multicolumn{5}{|c|}{ Autonomic symptoms } \\
\hline & & & & & & & Superficial & Deep & & Pupil & $\mathrm{OH}$ & Perspiration & Constipation & Impotence \\
\hline 1 & 29 & M & + & + & + & + & + & - & + & + & - & - & - & - \\
\hline 2 & 30 & $\mathrm{~F}$ & + & + & + & + & + & - & + & - & - & - & - & \\
\hline 3 & 39 & $\mathrm{M}$ & Diarrhoea & + & + & + & - & - & - & - & - & - & - & - \\
\hline 4 & 57 & M & + & + & + & + & - & + & + & - & - & - & - & - \\
\hline 5 & 63 & M & + & + & + & + & + & - & + & - & - & - & - & - \\
\hline 6 & 8 & $\mathrm{~F}$ & + & + & + & ++ & - & - & - & - & - & - & - & \\
\hline 7 & 11 & M & + & + & + & ++ & + & - & - & - & - & - & - & - \\
\hline 8 & 13 & $M$ & Diarrhoea & + & + & ++ & - & - & - & - & - & - & - & - \\
\hline 9 & 16 & $M$ & Diarrhoea & Axonal & + & ++ & - & - & - & - & - & - & - & - \\
\hline 10 & 23 & $\mathrm{~F}$ & Diarrhoea & + & + & ++ & + & - & - & - & - & - & - & \\
\hline 11 & 29 & $\mathrm{~F}$ & Diarrhoea & + & + & ++ & - & - & - & - & - & - & - & \\
\hline 12 & 31 & M & - & + & + & ++ & + & + & - & - & - & - & - & - \\
\hline 13 & 33 & $\mathrm{M}$ & - & + & + & ++ & - & - & - & - & - & - & - & - \\
\hline 14 & 43 & $\mathrm{~F}$ & Diarrhoea & Axonal & + & ++ & - & - & + & - & - & - & - & \\
\hline 15 & 57 & M & - & + & + & ++ & ++ & + & + & - & - & - & - & \\
\hline 16 & 59 & M & + & + & + & ++ & ++ & ++ & + & - & - & - & - & - \\
\hline 17 & 8 & M & + & + & + & +++ & - & - & + & - & - & - & + & \\
\hline 18 & 22 & M & + & + & + & +++ & + & + & + & + & - & - & - & - \\
\hline 19 & 29 & $\mathrm{~F}$ & - & + & + & $+++\star$ & + & - & + & - & - & - & - & \\
\hline 20 & 33 & $\mathrm{M}$ & Diarrhoea & + & + & $+++^{\star}$ & + & - & + & - & - & - & + & - \\
\hline 21 & 42 & M & - & Axonal & -Normal & +++ & - & - & + & + & - & - & - & + \\
\hline 22 & 42 & M & - & + & + & $+++\star$ & ++ Pain & ++ & + & - & - & + & - & - \\
\hline 23 & 44 & $\mathrm{~F}$ & + & + & + & $+++^{\star}$ & - & - & + & + & - & - & - & \\
\hline 24 & 47 & $\mathrm{~F}$ & + & + & + & $+++\star$ & + & - & + & - & - & - & - & \\
\hline 25 & 50 & $\mathrm{M}$ & - & + & + & +++ & - & - & - & - & - & - & - & - \\
\hline 26 & 61 & M & Diarrhoea & Axonal & + & $+++^{\star}$ & + & - & + & + & - & - & - & - \\
\hline 27 & 61 & $\mathrm{M}$ & + & + & + & $+++^{\star}$ & + & - & + & - & - & - & - & - \\
\hline 28 & 69 & $\mathrm{~F}$ & Herpes zoster & + & + & $+++^{\star}$ & ++ & + & + & - & - & - & + & \\
\hline
\end{tabular}

$+=$ mild $++=$ moderate $+++=$ severe ${ }^{\star}=$ mechanical ventilation; $\mathrm{NCS}=$ nerve conduction study; pupil = pupillary abnormality; OH = orthostatic hypotension; succeeding days; noct $=$ nocturia $;$ poll $=$ pollakisuria $;$ urg $=$ urgency; inco $=$ incontinence $;$ diff $=$ difficulty of voiding; $\pm=$ transient; $P P=$ plasmapheresis; PRL $=60$

and showed both superficial and deep modalities in six. These sensations seemed to be involved with severe motor deficits in our patients with Guillain-Barré syndrome. Cranial nerves were disturbed in 18, causing facial diplegia, swallowing difficulty, and abnormal extraocular movements. Nerve conduction studies showed that 24 patients had multifocal demyelination in more than one nerve at the distal and proximal ends (nerve roots) or in the intermediate portion, which showed up as temporal dispersion or conduction block, reduced amplitude, slowed conventional or terminal conduction velocity, and prolonged or absent $\mathrm{F}$ responses. ${ }^{12}$ Only four patients were considered to have the axonal form. They had reduced motor evoked amplitudes, but slowing of conduction velocity was spared. ${ }^{13}$ Examination of CSF showed cytoalbuminological dissociation in all but one patient (case 21) during the course of the disease. No one had a disturbance of consciousness, extensor plantar response, or any other sign of CNS involvement. Of autonomic disturbances other than micturitional ones, five patients had pupillary distur- bance, one perspiratory disturbance, three constipation, and one impotence.

Micturitional symptoms were noted and neurological examinations made repeatedly during the patient's stay in hospital. The symptoms consisted of nocturnal or diurnal urinary frequency, sensation of urgency, urinary incontinence and enuresis, difficulty in voiding (including urinary hesitation and prolongation), and urinary retention. The micturitional status of patients with an indwelling urinary catheter was evaluated at least one week after removal of the catheter. Patients with urinary symptoms did not have an apparent urinary tract infection. Patients under 10 years of age did not have recent histories of enuresis. Urodynamic studies were performed on four symptomatic patients, on two of whom the studies were repeated. None of the male patients studied had apparent prostatic hypertrophy on rectal digital examination and ultrasonography. Urodynamic studies consisted of uroflowmetry, measurement of residual urine, urethral pressure profilometry, medium fill water cystometry and external sphincter EMG.

Table 2 Results of urodynamic studies

\begin{tabular}{|c|c|c|c|c|c|c|c|c|c|c|c|c|c|c|}
\hline $\begin{array}{l}\text { Patient } \\
\text { No }\end{array}$ & $\begin{array}{l}\text { Age } \\
\text { (y) }\end{array}$ & Sex & Period $^{\star}$ & $\begin{array}{l}\text { Micturitional symptoms at } \\
\text { the time of urodynamic } \\
\text { studies }\end{array}$ & Flow $\downarrow$ & $\begin{array}{l}R U \\
(\mathrm{ml})\end{array}$ & $\begin{array}{l}\text { UPmax } \\
(\mathrm{cm} \\
\left.\mathrm{H}_{2} \mathrm{O}\right)\end{array}$ & $\begin{array}{l}F D V \\
(m l)\end{array}$ & $\begin{array}{l}M D V \\
(m l)\end{array}$ & $\begin{array}{l}\text { Detrusor } \\
\text { hyperreflexia }\end{array}$ & $\begin{array}{l}\text { Detrusor } \\
\text { areflexia }\end{array}$ & $\begin{array}{l}\text { Absent } \\
\text { BCR }\end{array}$ & $\begin{array}{l}\text { Non-relaxing } \\
\text { sphincter }\end{array}$ & $\begin{array}{l}\text { Neurogenic } \\
\text { change }\end{array}$ \\
\hline 14 & 43 & $\mathrm{~F}$ & 10 days & Mild stress incontinence & NP & 0 & $\mathrm{NP}$ & 189 & 410 & - & - & + & - & - \\
\hline 17 & 8 & M & 6 weeks & $\begin{array}{l}\text { Pollakisuria, urge } \\
\text { incontinence, voiding } \\
\text { difficulty }\end{array}$ & + & 30 & NP & $30 \downarrow$ & $60 \downarrow$ & + & - & - & - & NP \\
\hline \multirow[t]{3}{*}{21} & 42 & $M$ & 3 weeks & Retention & $\mathrm{NP}$ & $\mathrm{NP}$ & $105 \uparrow$ & 250 & 320 & + & - & - & - & - \\
\hline & & & 4 weeks & Voiding difficulty & $\mathrm{NP}$ & 100 & $40 \downarrow$ & $50 \downarrow$ & 290 & + & - & - & - & - \\
\hline & & & 6 weeks & Voiding difficulty (mild) & $\mathrm{NP}$ & 70 & 80 & 260 & 450 & - & - & - & - & NP \\
\hline \multirow[t]{2}{*}{27} & 61 & M & 3 weeks & Retention & $\mathrm{NP}$ & $\mathrm{NP}$ & NP & $600<$ & & - & + & $\mathrm{NP}$ & NP & $\mathrm{NP}$ \\
\hline & & & 3 months & None & - & 0 & 68 & $100 \downarrow$ & 270 & - & - & - & - & - \\
\hline
\end{tabular}

^Period before urodynamic studies.

Flow $\downarrow=$ decreased maximum or average uroflow rate according to Siroky's nomogram; NP=not performed; $\downarrow=$ value below the normal range; RU=residual urine (normal $<30 \mathrm{ml}$ ); $\uparrow=$ value above the normal range; UPmax $=$ maximum urethral closure pressure $\left(41<\right.$ normal $<82 \mathrm{~cm} \mathrm{H}_{2} \mathrm{O}$ ); FDV $=$ first desire to void $(100<$ normal $<300 \mathrm{ml}) ; \mathrm{MDV}=$ maximum desire to void $(200<$ normal $<600 \mathrm{ml}) ; \mathrm{BCR}=$ bulbocavernosus reflex. 
Table 1 continued

\begin{tabular}{llllllll}
\hline \multicolumn{2}{l}{ Micturitional symptoms } & & & & & \\
\hline Noct & Poll & Urg & Inco & Diff & Ret & Therapy & Recovery \\
\hline- & - & - & - & - & - & PP & Good \\
- & - & - & - & - & - & - & Good \\
- & - & - & - & - & - & $\gamma$-Globulin & Good \\
- & - & - & - & - & - & PP & Good \\
- & - & - & - & - & - & - & Fair \\
+ & + & + & Urge & - & - & - & Good \\
- & - & - & - & - & - & - & Good \\
- & - & - & - & - & - & - & Good \\
- & - & - & - & - & - & $\gamma$-Globulin & Poor \\
- & - & - & - & - & - & $\gamma$-Globulin & Good \\
- & - & - & - & - & - & - & Good \\
- & - & - & - & - & - & - & Good \\
- & - & - & - & - & - & - & Good \\
- & - & - & Stress & + & \pm & PP & Poor \\
- & - & - & - & - & - & PRL & Good \\
+ & + & + & - & + & - & - & Poor \\
+ & - & + & Urge & + & - & PRL & Good \\
- & - & - & - & - & - & $\gamma$-Globulin & Fair \\
- & - & - & - & - & - & PP & Fair \\
- & - & - & - & - & - & - & Good \\
- & - & - & - & + & \pm & - & Fair \\
- & - & - & - & - & - & PP & Fair \\
- & - & - & - & - & - & $\gamma$-Globulin & Fair \\
- & - & - & - & - & - & - & Good \\
- & - & - & - & - & - & $\gamma$-Globulin & Good \\
- & - & - & - & - & - & - & Fair \\
- & - & - & - & + & \pm & Pulse & Good \\
- & - & - & - & + & - & PP & Good \\
\hline
\end{tabular}

pulse $=$ methylprednisolone $(1 \mathrm{~g}$ on 3 succeeding days $) ; \gamma$-globulin $=\gamma$-globulin $(20 \mathrm{~g}$ on 5 $\mathrm{mg}$ /day prednisolone.

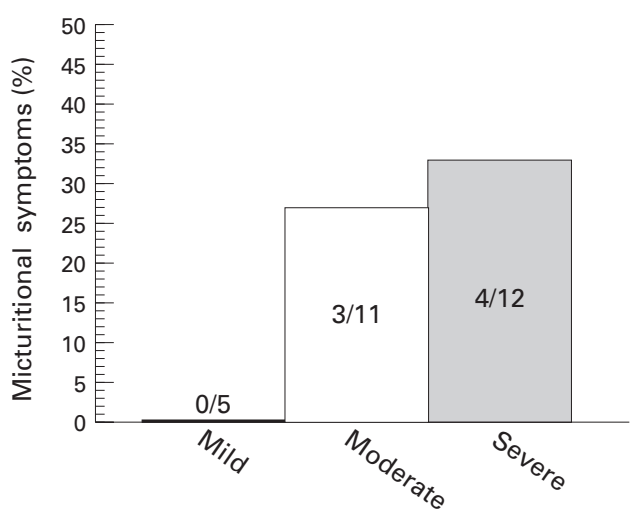

GBS $n=28$

Figure 1 Relation between muscle weakness and micturitional symptoms. Micturitional symptoms in Guillain-Barré syndrome (GBS) seem to be more common in patients with severe weakness than in those with mild weakness (non-significant).

Uroflow curves were evaluated according to Siroky's nomogram. ${ }^{14}$ The normal range of urodynamic studies were residual urinary volume $<30 \mathrm{ml}$; maximum urethral closure pressure $>41 \mathrm{~cm} \mathrm{H}_{2} \mathrm{O}$ and $<82 \mathrm{~cm} \mathrm{H}_{2} \mathrm{O}$; first desire to void (FDV) $>100 \mathrm{ml}$ but $<300 \mathrm{ml}$, and maximum desire to void (MDV) $>200 \mathrm{ml}$ but $<600 \mathrm{ml}$. Increased FDV, or MDV, or both indicates disturbed bladder sensation. The methods and definitions used for the urodynamic studies conformed to the standards proposed by the International Continence Society ${ }^{15}$ described elsewhere. ${ }^{16}$ Informed consent was obtained from all the patients before the urodynamic studies were made.

\section{Results}

MICTURITIONAL HISTORY FINDINGS

Accurate history taking showed that seven of 28 patients $(25 \%)$ with Guillain-Barré syn- drome had micturitional symptoms (table 1), being notable in five of $24(21 \%)$ with the demyelinating form of Guillain-Barré syndrome and in two of four $(50 \%)$ with the axonal form. The major symptoms of the patients were voiding difficulty (six), then transient urinary retention (three), nocturnal urinary frequency (three), urinary urgency (three), diurnal urinary frequency (two), urge urinary incontinence (two), and stress incontinence (one). Micturitional symptoms in Guillain-Barré syndrome seemed to be more common in patients with severe weakness than in those with mild weakness, but there was no significant difference (fig 1). These micturitional symptoms appeared after weakness occurred and improved gradually along with the other neurological signs. All three patients with urinary retention became able to urinate during the course of the disease.

\section{URODYNAMIC STUDY}

Urodynamic studies were made of four patients. Two underwent repeated study. All the patients had micturitional symptoms: two urinary retention; one voiding difficulty; one urinary urgency; one diurnal urinary frequency; and one stress incontinence (table 2). Uroflowmetry was performed on two patients, one of whom (case 16) had decreased maximum and mean uroflow rates. Residual urinary volume was measured for all the patients except those with urinary retention. Residual urine $>30 \mathrm{ml}$ was noted in one (case 17), and one patient with urinary retention (case 21), who became able to urinate, had a residual urine volume first of $100 \mathrm{ml}$, then $70 \mathrm{ml}$, and then zero during the course of the disease. Urethral pressure profilometry was performed on two patients. The maximum urethral closure pressure of one patient (case 21) was increased at three weeks, then decreased at four weeks, becoming normal at six weeks after the onset of Guillain-Barré syndrome. Water cystometry was performed on all the patients; bladder volume at FDV or MDV was decreased in three and increased in one (case 27). Two patients had bladder overactivity during urinary storage (fig 2), one of whom (case 21) had normal storage six weeks after onset of Guillain-Barré syndrome. One patient had bladder areflexia (case 27) on voiding, but became normal during the course of the disease. External sphincter EMG showed the absence of bulbocavernosus reflex in one patient (case 14). Neither non-relaxing sphincter on voiding nor neurogenic changes in sphincter motor unit potentials were found in our patients.

\section{Discussion}

There is controversy as to whether micturitional disturbance should or should not be a factor in the diagnosis of Guillain-Barré syndrome. ${ }^{4}$ Truax $^{17}$ reported that a common misconception is that bladder dysfunction is rare in Guillain-Barré syndrome. An earlier review of the clinical features of the syndrome showed that micturitional function was present in $6 \%-40 \%$ of the patients studied. ${ }^{17}$ This is 


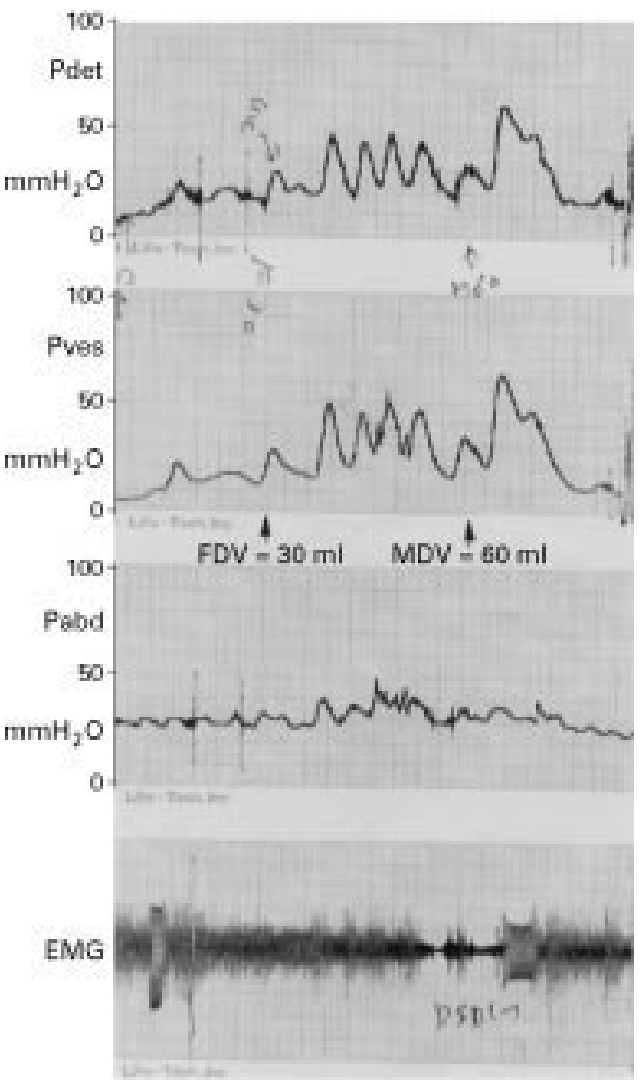

Figure 2 Urodynamic study findings in case 17. Simultaneous recordings of intravesical pressure (Pves), intra-abdominal pressure (Pabd), subtracted detrusor pressure (Pdet), and external urethral sphincter EMG. The first desire to void (FDV) was $30 \mathrm{ml}$ and the maximum desire to void (MDV) $90 \mathrm{ml}$. There is a wave form repetitive pressure rise, indicative of bladder overactivity.

close to the $25 \%$ found in the original reports of Guillain et $a l,{ }^{6} 7$ and the $25 \%$ reported here. Our study also showed the presence of micturitional disturbance in five of $24(21 \%)$ patients with the demyelinating form and two of four $(50 \%)$ patients with the axonal form of Guillain-Barré syndrome, the number of patients being too small for statistical analysis. Lichtenfeld ${ }^{18}$ found urinary retention in one third of patients who needed ventilatory assistance. Our study also showed that micturitional symptoms are more common in patients with severe weakness, indicative of a relation between micturitional disturbance and the severity of Guillain-Barré syndrome. The major symptoms in our patients were voiding difficulty in six, transient urinary retention in three, nocturnal urinary frequency in three, and urge urinary incontinence in two, evidence of both evacuating and storage disorders.

Urodynamic data on Guillain-Barré syndrome are available in only a few reports. ${ }^{8910}$ Bladder areflexia and disturbed bladder sensation are common, and non-relaxing urethral sphincter with neurogenic change is another frequent factor. ${ }^{8} 9$ In our study, water cystometry showed bladder areflexia in one of four patients with disturbed bladder sensation, but there was a tendency to return to normal during the course of the disease. Detrusor areflexia commonly occurs in diabetic polyneuropathy ${ }^{19}{ }^{20}$ and indicates a postganglionic type of pelvic (para- sympathetic) nerve dysfunction that causes evacuation disorder. ${ }^{21}$ We also showed the absence of bulbocavernosus reflex in one patient, indicative of pudendal (somatic) nerve dysfunction. ${ }^{22}$ Guillain-Barré syndrome mainly affects the large myelinated fibres, but pathology studies have shown moderate to severe loss of small myelinated fibres and inflammatory cell infiltration in the lumbosacral spinal roots and thoracolumbar sympathetic chain. ${ }^{52} 24$ These urodynamic findings may reflect lumbosacral lesions that innervate the lower urinary tract.

Previously Wheeler et al, ${ }^{9}$ using carbon dioxide cystometry, found bladder overactivity in three of seven patients with Guillain-Barré syndrome. Two of their patients with bladder overactivity, however, had extensor plantar responses, which raises questions about the diagnosis. He stated that the other patient did not have the extensor plantar response. Water cystometry findings in our study showed bladder overactivity in two patients with clinical and neurophysiologically definite GuillainBarré syndrome. One patient (case 17), an 8 year old boy with severe weakness of the limbs, had difficulty in voiding and urge incontinence. In childhood, some boys and girls with enuresis occasionally have bladder overactivity. This patient, however, did not have a recent history of enuresis. His bladder capacity decreased to $60 \mathrm{ml}$ with bladder overactivity, but afterwards his micturitional symptoms gradually improved together with his neurological signs. The second patient (case 21), a 42 year old man, had severe weakness of the limbs. When the urodynamic study disclosed bladder overactivity, he was in a state of urinary retention. After becoming able to urinate, he still had a residual urinary volume of $100 \mathrm{ml}$ indicative of evacuation disorder, which is known to occur in patients with bladder overactivity. ${ }^{25}$ Follow up studies disclosed that bladder overactivity returned to normal during the course of the disease. Bladder overactivity is usually seen in suprasacral spinal cord or cerebral lesion and is indicative of the supranuclear type of pelvic nerve dysfunction. ${ }^{21}$ Although no brain or spinal MRI was performed, these two patients showed no disturbance of consciousness, extensor plantar response, or other evidence suggestive of CNS involvement. Although present in only a few patients, we consider bladder overactivity to be caused by Guillain-Barré syndrome. Cardiovascular overactivity and underactivity have been recognised in GuillainBarré syndrome. ${ }^{12}$ Labile hypertensive or hypotensive arterial pressure, postural hypotension, bradyarrhythmias, or tachyarrhythmias may occur. ${ }^{3}$ A parasympathetic (vagal) afferent defect of the baroreflex is postulated to contribute to cardiovascular labilities. ${ }^{2}$ Bladder sensation, indicative of afferent pelvic nerve function, however, was preserved in the two patients with bladder overactivity. Bladder overactivity or "detrusor instability" has occasionally been reported in patients with cauda equina or pelvic plexus lesions, such as those seen in simple hysterectomy ${ }^{26}$ and lumbar disc prolapse. ${ }^{27} 28$ These findings show that bladder overactivity may also occur in peripheral nerve 
lesions, with probable pelvic nerve irritation, ephaptic transmission, or some other underlying mechanism.

1 Tuck RR, Mcleod JG. Autonomic dysfunction in GuillainBarré syndrome. f Neurol Neurosurg Psychiatry 1981;52:857-64.

2 Zochodne DW. Autonomic involvement in Guillain-Barré syndrome; a review. Muscle Nerve 1994;17:145-55.

3 McDougall AJ, McLeod JG. Autonomic neuropathy, 2; specific perpheral neu

4 Asbury AK, Arnason BG, Kapr HR, McFarlin DE. Criteria for diagnosis of Guillain-Barré syndrome. Ann Neurol 1978;3:565-6.

5 Arnason BGW, Soliven B. Acute inflamatory demyelinating polyradiculoneuropathy. In: Dyck PJ, Thomas PK eds, Peripheral neuropathy. 3rd ed. Philadelphia: WB Sounders, 1993:1437-97.

6 Guillain G, Barré JA, Strohl A. Sur un syndrome de radiculo-névrite avec hyperalbuminose du liquode céphalorachidien sans réaction cellulaire; remarques sur les caractéres cliniques et graphiques des réflexes tendineux Bulletins et Mémoires de la Société Médicale des Hôpitaux de Paris 1916;40:1462-70.

7 Guillain G. Radiculoneuritis with acellular hyperalbuminosis of the cerebrospinal fluid. Archives of Neurology and Psychiatry 1936;36:975-90.

8 Kogan BA, Solomon MH, Diokno AC. Urinary retention secondary to Landry-Guillain-Barré syndrome. F Urol 1981;126:643-4.

9 Wheeler JS, Siroky MB, Pavlakis A, Krane RJ. The urological aspects of the Guillain-Barré syndrome. F Urol cal aspects of the

10 Chung K, Tokinobu H, Tanabe H, Tomoishi J. Urinary disturbance in Guillain-Barré syndrome. Autonomic Nervous
System (Tokyo) 1988;25:626-32. (In Japanese.)

11 Guillain-Barré syndrome steroid trial group. Double-blind trial of intravenous methylprednisolone in Guillain-Barré syndrome. Lancet 1993;341:586-90.

12 Donofrio PD, Albers,JW. AAEM minimonograph no 34 polyneuropathy; classification by nerve conduction studies and electromyography. Muscle Nerve 1990;13:889-903.

13 Feasby TE, Gilbert JJ, Brown WF, Bolton CF, Hahn AF, Koopman WF, Zochodne DW. An acute axonal form of Guillain-Barré polyneuropathy. Brain 1986;109:1115-26.
14 Siroky MB, Olsson CA, Krane RJ. The flow rate nomogram; 2. Clinical correlation. $\mathcal{F}$ Urol 1980;123:208-10.

15 Abrams P, Blaivas JG, Stanton SL, Andersen JT. The standardisation of terminology of lower urinary tract function; produced by the International Continence Society Commitee on Standardisation of Terminology. World $f$ Urol 1989;6:233-45.

16 Hattori T, Yasuda K, Kita K, Hirayama K. Voiding dysfunction in Parkinson's disease. Fapanese fournal of Psychiatry and Neurology 1992;46:181-6.

17 Truax B. Autonomic disturbance in the Guillain-Barré syndrome. Semin Neurol 1984;4:462-8.

18 Lichtenfeld P. Autonomic dysfunction in the Guillain-Barré syndrome. Am f Med 1971;50:772-80

19 Hattori T, Yasuda K, Kita K, Makino E, Hirayama K. Disturbance of micturition in patients with diabetes mellitus. Autonomic Nervous System (Tokyo) 1987;24:566-70. (In Japanese.)

20 Kaplan SA, Te AE, Blaivas JG. Urodynamic findings in patients with diabetic cystopathy f Urol 1995;153:342-4.

21 Wear LB. Cystometry. Urol Clin North Am 1974;1:45-67.

22 Davis L, Khan Z. Significance of electromyographic changes in the external urinary sphincter. Neurourol Urodyn 1986;5: 555-62.

23 Kanda T, Hayashi $H$, Tanabe $H$, Tsubaki $T$, Oda $M$. A fulminant case of Guillain-Barré syndrome; topographic and fibre size related analysis of demyelinating changes. $\mathcal{F ~} \mathrm{Neu}$ rol Neurosurg Psychiatry 1989;52:857-64.

24 Honavar M, Tharakan JKJ, Hughes RAC, Leibowitz S, Winer B. A clinicopathological study of the Guillain-Barré syndrome; nine cases and literature review. Brain 1991;114: $1245-69$.

25 Resnick NM, Yalla SV. Detrusor hyperactivity with impaired contractile function; an unrecognized but common cause of incontinence in elderly patients. $\mathcal{F A M A} 1987 ; 257: 3076-$ 81.

26 Parys BT, Woolfenden KA, Parsons KF. Bladder function after simple hysterectomy; urodynamic and neurological evaluation. Eur Urol 1990;17:129-33.

27 Cheek WR, Anchondo H, Raso E, Scott R. Neurogenic bladder and the lumber spine. Urology 1973;2.

28 Yamanishi T, Yasuda K, Tojo M, Sakakibara R, Hattori T, Shimazaki J. Detrusor hyperreflexia in the lower lumber lesion. 33rd Annual Scientific Meeting of the International Society of Paraplegia. Kobe, Japan: 1993;146. 